\title{
The Dual Function of Q-Marker in Korean: \\ Evidence from Unselected Embedded Questions
}

\author{
Myung-Kwan Park $^{\dagger}$ \\ Dongguk University
}

\begin{abstract}
This study investigates the distribution of unselected embedded questions (EQs). Cross-linguistically, with the exception of certain restricted adverbial uses, EQs tend to appear with question-embedding predicates. However, Kim \& Tomioka (2014) noted that EQs in Korean/Japanese are in wider distribution compared to English. Comparing Korean/Japanese with Chinese/English, this study shows that the difference between these two groups regarding the availability of EQs lies in the overt realization of an interrogative complementizer or Q-marker. Korean/Japanese deploys an overt form of Q-marker that can convert/ grammaticalize into an adverbializer; specifically, it has a dual function, primarily as a Q-marker and secondarily as an adverbializer. Contrarily, Chinese/English does not, which restricts the use of EQs in these two languages. Along this line of analysis, the study also suggests that indefinites in Korean derived from wh-phrases plus Q-markers are fed by the same strategy of deriving unselected EQs.
\end{abstract}

Keywords: Q-marker, unselected indirect question, interrogative complementizer, adverbializer, indeterminate/indefinite

\section{Introduction}

In Korean, the sentence-final morpheme '-ci' in root clauses can be used as a Q-marker, as in (1):

(1) Cheli-nun ecey mwues-ul sa-ass-ci?

Cheli-TOP yesterday what-ACC buy-PST-Q

'What did Cheli buy yesterday?'

However, '-ci' cannot be used as a Q-marker in embedded clauses; instead,

† Corresponding author: parkmk@dongguk.edu

Copyright (C) 2021 Language Education Institute, Seoul National University.

This is an Open Access article under CC BY-NC License (http://creative-commons.org/licenses/by-nc/4.0). 
'-nunci' ('-nci' or '-lci' when with the preceding copula) is used as such, as in (2):1)

(2) Na-nun [Cheli-ka ecey mwues-ul sa-ass-* ${ }^{*}$ - $/$-nunci]

I-TOP Cheli-NOM yesterday what-ACC buy-PST-Q/-Q

kwungkumha-ta.

wonder-DCL

'I wonder what Cheli bought.'

Like other indirect/dependent question clauses, '-nunci' clauses occur with question-embedding/selecting higher verbs like 'kwungkumha-' as in (2). However, the peculiar distribution of embedded question clauses in Korean is that they can occur on their own without question-selecting higher verbs, as in (3) and (4):

(3)

\begin{tabular}{|c|c|c|c|c|}
\hline [Palam-i & elmana & sey-key & pwunun-ci] & kaloswu \\
\hline wind-NOM & how much & strong-ly & blow-Q & street tree \\
\hline $\begin{array}{l}\text { kacitul-i } \\
\text { branches-NO }\end{array}$ & $\begin{array}{ll}\text { kkekk } & \text { were }\end{array}$ & & & \\
\hline
\end{tabular}

'(Lit.) (I observed) how strongly the wind blew; the street trees had their branches broken.'

(4) [Mwues-i thullyess-nunci] tap-ul macchwe poca. what-NOM was wrong-Q answer-ACC match '(Lit.) (To see) what was wrong, match an answer with a question.'

The underlined clauses in (3) and (4) are what Kim \& Tomioka (2014) term unselected embedded questions (EQs).

English also has unselected EQs, as follows.

(5) [Whether Tom leaves or not] / [whether Tom leaves or stays] / [whatever Tom does], Jon won't stay past midnight. (Gawron, 2001; Rawlins, 2006)

1) In fact, the Q-marker '-nunci' can also occur in indirect question-like root clauses, as follows:

(i) Kohyangey-nun cal tanyeosyess-nunci?

Hometown-TOP well been to-Q

'Did you have a good trip to your hometown?'

(ii) Cey tongsayng-i il-un calha-nunci-yo?

my younger brother-NOM job-TOP well.do-Q-HEAR.HON

'Are your brother good at his job?' 
But as noted by Gawron (2001) and Rawlins (2006), their use is restricted to concessive conditionals or unconditionals. ${ }^{2)}$

Crucially, however, question clauses with ordinary wh-phrases in English cannot serve as unselected EQs. Thus, the literal English sentences of (3) and (4) are outrightly ungrammatical.

(6) *How strongly the wind blew, the street trees had their branches broke.

(7) *What was wrong, match an answer with a question.

This paper investigates the cross-linguistic difference between Korean/Japanese and English/Chinese concerning the availability EQs. Section 2 rehearses Kim \& Tomioka's (2014) recent analysis of EQs in Korean/Japanese, and moves on to set the issue that is going to be addressed in the later part of this paper. Section 3 proposes that the difference between Korean/Japanese and English/Chinese in the distribution of EQs follows from the deployment of overtly realized interrogative complementizers in the former but not in the latter; at the same time, overt Q-markers in Korean/Japanese can also be employed as adverbializers that turn EQ clauses into adverbial clauses. Section 4 shows that the same strategy of deriving unselected EQs is capitalized on in the historical development of Korean indefinites composed of wh-phrases and Q-markers; they started as forming truncated indirect question clauses, which in turn have grammaticalized into indefinite nominals, with Q-markers in this process developing into nominal particles encoding disjunction. Section 5 wraps up with a conclusion.

\section{Setting the Issue}

Kim \& Tomioka (2014) note two types of unselected embedded questions, illustrating them with the examples in (8) and (9). The two examples are taken from Kim \& Tomioka (ibid.) with some modification.

2) According to Rawlins' (2006) analysis of them, unconditionals are 'if'-less conditionals; The Spec of the complementizer 'if' can instead be occupied by 'wh-+ever' compounds like 'whatever' in (5). 
(8)

$\begin{array}{llll}{[\mathrm{Pi}-\mathrm{ka}} & \text { w-ass-nunci }] & \text { matang-i } & \text { ceceiss-ta. } \\ \text { rain-NOM } & \text { come-PST-Q } & \text { ground-NOM } & \text { wet-DCL }\end{array}$

'(Lit.) [Whether it rained] the ground is wet,' or 'the ground is wet and I wonder whether it rained.'

(9) [Pi-ka w-ass-nunci $]$ Paul-un pakk-ul naytapo-ass-ta. rain-NOM come-PST-Q Paul-TOP outside-ACC look-PST-DCL '(Lit.) [Whether it rained] Paul looked outside,' or 'Paul looked outside to see if it rained.'

While the two sentences look analogous, they are different in light of the relationship that unselected EQs have with the main clauses. In (8), the EQ describes a reason/cause for the situation denoted by the matrix clause. By contrast, in (9) 'to know' the answer to the EQ represents a motivation/purpose for the matrix clause event.

Kim \& Tomioka (2014) go on to characterize the first type of unselected EQs as in (8) as speaker-oriented ones (SEQ's), suggesting that they are interpreted at the Conventional Implicature tier of the multi-dimensional system proposed by Potts (2005). Thus, they have the following characteristics:

(10) a. SEQ's are speaker-oriented.

b. They are not deniable

c. They are lexically triggered by a comma intonation, like supplement clauses in Potts (2005).

d. They are anti-backgrounded.

First, it is the speaker that sees the EQ as a reason/cause for the matrix clause event. Second, they cannot be negated as in (11), as noted by Kim \& Tomioka (2014):

* $\mathrm{Pi-ka}$ w-ass-nunci an w-ass-nunci $]$ matang-i ceceiss-ta.
rain-NOM come-PST-Q ground-NOM wet-DCL
'(Lit.) [Whether it rained or not ] the ground is wet,'

Third, there is an implicit comma where the EQ is adjoined to the main clause; This COMMA feature turns at-issue content into a Conventional Implicature. 
Fourth, Kim \& Tomioka (2014) suggest that discourse functions of SEQ's are analogous to those of 'self-addressing' questions. By asking a self-addressing question, the speaker invites but does not demand the answer to it; it just leads to inquisitive update of the speaker's beliefs.

On the other hand, Kim \& Tomioka (2014) identify the second type of unselected EQs as in (9) as agent-oriented ones (AEQ's), noting the following characteristics:

(12) a. AEQ's are agent-oriented.

b. They contribute to the at-issue meaning.

c. They are embedded inquisitive update acts.

d. The rhetorical relation Explanation in the sense of Lascarides and Asher (1993) may capture the semantic relation between an AEQ and its host clause.

First, as in (13) of Japanese (taken from Kim \& Tomioka (2014)), it is not the referent of the grammatical subject but that of the agent argument who wants to know the answer to the $\mathrm{EQ}$.

(13) [Matigai-ga nai-ka] sono-syorui-wa nan-nin-mo-no [error-NOM NEG-Q] that-document-TOP how.many-CL-even-Gen kensain-niyotte yom-are-ta. examiner-by read-Pass-Past

'(To see) whether it contains any errors, that document was read by many examiners.'

Second, AEQ's behave as an at-issue expression, in that they can be denied as in (14) (also taken from Kim \& Tomioka (2014)):
A: Paul-i [pi-ka w-ass-nunci] pakk-ul naytapo-ass-ta. Paul-NOM rain-NOM come-PST-Q outside-ACC look-PST-DCL '(Lit.) 'Paul looked outside to see whether it rained.'
B: Ani, Paul-un [nwu-ka o-nunci] po-lyeko-ha-yss-e. No, Paul-TOP who-NOM come-Q see-Purpose-do-PST-DCL 'No, Paul intended to see who's coming (when he looked outside).'

Third, AEQ's are also a self-addressing question that the referent of the relevant 
agent had when he engaged in the action described in the main clause, thereby leading to inquisitive update of the agent's belief worlds. Fourth, still noting some problems with their proposed analysis, Kim \& Tomioka (2014) tentatively suggest that AEQ's can function as an explanation of the action depicted in their host clause.

Though Kim \& Tomioka (2014) importantly articulate the semantic characteristics of the two types of unselected EQs in Korean/Japanese, what is critically missing in their analysis is the explanation for why some languages like Korean/Japanese allow unselected EQs, but why some languages like English do not. To illustrate some more languages allowing unselected EQs, Özy1ldiz (2018) report that they are also available to Turkish and Uyghur (an official language of the Xinjiang Uyghur Autonomous Region), as in (15) and (16):

(15) Turkish:

$\begin{array}{llllll}\text { Ali } & \text { [anne-si } & \text { gel-di } & \text { mi } & \text { diye }] & \text { kap1-y1 } \\ \text { Ali } & \text { mother-3S.POSS } & \text { arrive-PST.3S } & \text { POLQ } & \text { DIYE } & \text { door-ACC }\end{array}$
aç-t1.

open-PST.3S

'Ali opened the door wondering whether his mother had arrived.'

(16) Uyghur:

Ali $\left[\begin{array}{lll}\mathrm{u} & \text { yeng-al-i-mu dep } & \text { bilet tashli-ghili }\end{array}\right.$

Ali he win-ABIL-3S.POSS-POLQ DEP ballot throw-PURP bar-di.

go-PST.3S

'Ali cast his ballot asking himself whether he could win.'

By contrast, Chinese behaves in the parallel way as English, disallowing unselected EQs, as in (17) (19):

(17) Wo zai shangchang zhuan-le-zhuan *(kankan) [mai xie shenme]. $\mathrm{i}$ at store turn-PERF-turn see buy some what

'I browsed about the store to see what to buy.'

(18) Wo wang chuangwai chou-le-chou *(kankan) [xia-mei-xia-yu]. $i$ through window-out see-PERF-see see rain-no-rain 'I looked out through the window to see whether it rained. 
(19)

$\begin{array}{lllll}* \text { (Bu-zhidao) } & \text { [chi-le } & \text { shenme } & \text { Zhang San duzitong. } \\ \text { not-know } & \text { eat-PERF } & \text { what } & \text { Zhang San stomachache }\end{array}$

'I don't know what he ate, but Zhang San had a stomachache.

In these examples of Chinese, question-selecting verbs such as 'kankan' or '(bu-)zhidao' are required with the following EQs. Recall that in Korean/Japanese and Turkish/Uyghur, such verbs are not.

It is to be noted, at the same time, that Kim \& Tomioka's (2014) semantic characterization of SEQ's/AEQ's and their relations with their host main clauses does not provide any effective account for this cross-linguistic difference in terms of the distribution of unselected EQs. In the next section, we propose that the overt realization of a Q-marker is instrumental, and that such an overt Q-marker serves a dual function both as a complementizer and as an adverbializer.

\section{Towards an Account}

To account for the distribution of unselected EQs in Korean/Japanese and Turkish/Uyghur, we propose that a Q-marker in these languages has a dual function: primarily as a Q-marker and at the same time as an adverbializer. Note that unlike these languages, English/Chinese only employs an implicit Q-marker that cannot serve the role of an adverbializer, thus EQs in English/Chinese needing to be selected, aside from the limited concessive conditional use of clauses headed by 'whether' or 'wh-+ever' compounds in English.

The instantiation of a complementizer as an adverbializer is nothing unusual in Korean. Rhee (2017) documents various functional extensions of the declarative complementizer (DEC-COMP) '-tako' (the combination of the declarative mood marker '-ta' with the quotative marker/subordinator '-ko'). The declarative complementizer '-tako' in (20a) occurs at the end of the complement clause. The same form or another variant form '-lako' in (20b) and (20c) can covert to an adverbializer, encoding reason or concession into the clause attached with it:

(20) a. DEC-COMP '-ta+ko':

Ku-nun [hawai ka-nta+ko] calangha-nta
he-TOP Hawaii go-DCL-Sub boast-DCL
'He boasts that he is going to Hawaii.'


(< (Lit.) He, saying, "(I) go to Hawaii," boasts.)

b. DEC-COMP '-ta+ko' > Reason marker (REAS):

Ku-nun [pappu-ta+ko] setwulu-nta

he-TOP be.busy-REAS hurry-DCL

'He hurries because he is busy.

(< (Lit.) He, saying, "(I) am busy," hurries.)

c. DEC-COMP '-la+ko'> Concessive marker (CONC):

[Uysa-la+ko] pyeng-ul ta kochi-nun ke-y

doctor-CONC illness-ACC all cure-ADN NOMZ-NOM

ani-ta.

be.not-DCL

'Even doctors cannot cure all illnesses.'

(< (Lit.) Saying, "(he) is a doctor," (he) cannot cure all illnesses.') $)^{3)}$

It can be noted that like the quotative marker or subordinator '-ko', the homophonous (predicate) coordination marker '-ko' can also covert to an adverbializer, as in (21b) in contrast to its canonical coordinative use in (21a):

(21) a. Cheli-ka khi-ka khu-ko Yengi-ka khi-ka cakta.

C.-NOM height-NOM tall-CONJ Y.-NOM height-NOM short-DCL

'Cheli is tall, and Yengi is short.'

b. Halmeni-kkeyse-nun sanghan umsik-ul tusi-ko

grand mother-HON-TOP rotten food-ACC eat-CONJ

thal-i na.sy-ess-ta.

trouble occur.HON-PST-DCL

3) Rhee (2017) adds that the INTerrogative complementizer '-nya+ko' and the IMPerative complementizer '-la+ko' can also covert/grammaticalize into an adverbializer, encoding pejoration and purpose on the clause attached with it, as in (i) and (ii):

(i) INT-COMP '-nya+ko' > Pejorative marker (PEJ):

Thomatho-nya+ko toykey cak-ney

tomato-PEJ very be.small-INTJ

'What a small tomato!'

(< (Lit.) Saying, "(\{Is it, Are you $\})$ a tomato?", (\{it is, you are $\}$ very small.)

(ii) IMP-COMP '-la+ko' > Purposive marker (PURP):

Somwun-na-la+ko way kul-ay?

rumor-exit-PURP why do.so-END

'Are you trying to stir up a rumor?'

(< (Lit.) Why are you doing so, saying, "Let there be a rumor!"?) 
Returning to unselected EQs, the languages allowing them have overtly realized Q-markers, as repeated from above. The Q-markers are boxed in (22) (25):

(22) Korean:

[Mwues-i thullyess-nunci] tap-ul macchwe poca.

what-NOM was wrong-Q answer-ACC match

'(Lit.) (To see) what was wrong, match an answer with a question.'

(23) Japanese:

[Matigai-ga nai-ka] sono-syorui-wa nan-nin-mo-no

[error-NOM NEG-Q] that-document-TOP how.many-CL-even-Gen

kensain-niyotte yom-are-ta.

examiner-by read-Pass-Past

'(To see) whether it contains any errors, that document was read by many examiners.'

(24) Turkish:

$\begin{array}{lllll}\text { Ali } & \text { ganne-si } & \text { mi } & \text { diye] kap1-y1 }\end{array}$

Ali mother-3S.POSS arrive-PST.3S POLQ DIYE door-ACC

aç-tı.

open-PST.3S

'Ali opened the door wondering whether his mother had arrived.'

(25) Uyghur:

Ali [u yeng-al-i-mu dep] bilet tashli-ghili

Ali he win-ABIL-3S.POSS-POLQ DEP ballot throw-PURP

bar-di.

go-PST.3S

'Ali cast his ballot asking himself whether he could win.'

In these languages, Q-markers rather than a quotative marker or subordinator are instrumental in the adverbial interpretation of unselected EQs. Particularly, in Korean the EQ clause with the interrogative marker '-nunci' is construed as a vague or self-addressing question that need not be answered; at the same time, the interrogative marker now as an adverbializer has an additional function of connecting an unselected EQ clause to its host main clause. 
On top of the interrogative marker '-nunci', other Q-markers in Korean such as '-lci', '-na', '-lkka', and '-nyako' also have a dual function as a Q-marker-cumadverbializer, as in (26):

(26) a. Nay-ka myech tung-i-lci maum-ey-n kekceng-i katukhayssta. I-NOM what rank-COP-Q heart-in-TOP worry-NOM full '*(Wondering) what rank I am, my heart was full of worries.'

b. Kwangkyenpyeng-i eps-na kay-ka kemsa-lul patassta. rabies-NOM not.exist-Q dog-NOM examination-ACC received '*(To see) whether it contracted rabies, the dog went through an examination.'

c. Koki-ka caphi-lkka Cheli-nun kang-eyta kumwulul fish-NOM be caught-Q Cheli-TOP river-in net-ACC tencyepoassta. ${ }^{4)}$

threw

'*(To see) whether fish was caught, Cheli cast a net into the river.'

d. Selma kuleh-keyss-nyako Cheli-nun kokay-lul no way so-PST-Q Cheli-TOP head-ACC kyawuttwungha-yss-ta. 5 )

tilt-PST-DCL

'Cheli tilted his head, asking (himself) whether it is so.'

In stark contrast to the EQ-allowing languages, English and Chinese do not have an overt Q-marker, thus disallowing unselected EQs, as follows:

4) As noted by Kim \& Tomioka (2014), in Korean the Q-marker as an adverbializer cannot depict an event of the EQ that is simultaneous or concurrent with the main clause event, thus accounting for the unacceptability of the following example without the question-embedding predicate:

(i) [Onul mwues-ul ha-lkka] *(sayngkakha-mye) Cheli-nun achim pap-ul mekessta. Today what-ACC do-Q think-while Cheli-TOP breakfast-ACC ate '*(While wondering) what to do today, Cheli ate breakfast.'

5) Rhee (2017) reports instances of lexicalized adverbials in Korean, which are derived from combining the interrogative complementizer '-nyako' with the preceeding wh-phrases. They are illustrated below:

(i). i-key-weyn-ttek-i-nyako 'gladly' < 'saying, "What kind of cake is this?"'

(ii). al-key-mwe-nyako 'nonchalantly' < 'saying, "What should I know?"

(iii). mwusun-cis-i-nyako 'protestingly' < 'saying, "What kind of act is it?"'

(iv). mwusun-sol-i-nyako 'protestingly' < 'saying, "What kind of sound is it?"

(v). ku-key-eti-nyako 'appreciatively' < 'saying, "Where is it?" 
(27) Chinese:

$\begin{array}{lllll}* \text { (Bu-zhidao) } & \text { [chi-le } & \text { shenme } & \text { Zhang San } & \text { duzitong. } \\ \text { not-know } & \text { eat-PERF } & \text { what } & \text { Zhang San } & \text { stomachache }\end{array}$

'I don't know what he ate, but Zhang San had a stomachache.

(28) English:

'*(To see) [what was wrong], match an answer with a question.'

One caveat is in order regarding Chinese and English. As in (29), the so-called 'shi-bu-shi' question clause in Chinese is allowed as an unselected EQ.

(29) [Shi-bu-shi xiayu-le], di shi le. be-no-be rain-PERF ground wet PERF Whether it rained or not the ground was wet.

In keeping with Liu (2004), we assume that 'shi-bu-shi' can be base-generated at the Comp position, as evidenced by (30a-b):

(30) a. ?Wo xiang zhidao shi-bu-shi ni yao bangzhu wo? I want know be-not-be you want help I 'I wonder if you want to help me.'

b. Wo xiang zhidao ni shi-bu-shi yao bangzhu wo? I want know you be-not-be want help I 'I wonder if you want to help me.'

Thus, 'shi-bu-shi' in (29) of Chinese behaves on a par with 'whether' or 'wh-+ever compound' in concessive conditional or unconditional constructions of English, as in (31) repeated from (5):

(31) [Whether Tom leaves or not] / [whether Tom leaves or stays] / [whatever Tom does,] Jon won't stay past midnight.

(Gawron, 2001; Rawlins, 2006)

In summary, an interrogative complementizer in Korean/Japanese and Turkish/ Uyghur has a dual function, primarily as a $\mathrm{Q}$ marker and secondarily as an adverbializer: with the latter function encoding a reason/cause or motivation/ 
purpose, the complementizer in question connects an unselected EQ with its host main clause.

\section{An Extension: The Formation of Indefinites from Wh-phrases}

It is well known that in Korean, an indefinite expression can be created by combining a wh-word with a Q-marker such as '-nka' or '-nci', as follows.

\begin{tabular}{lll}
\hline \multicolumn{1}{c}{ wh- } & \multicolumn{1}{c}{+ -nka } & \multicolumn{1}{c}{+ -nci } \\
\hline \hline nwukwu 'who' & nwukwu-nka 'someone' & nwukwu-nci 'someone' \\
mwue(s) 'what' & mwue-nka 'something' & mwe-nci 'something' \\
encey 'when' & encey-nka 'sometime' & encey-nci 'sometime' \\
eti 'where' & eti-nka 'somewhere' & eti-nci 'somewhere' \\
ettehkey 'how' & ettehkey-nka 'somehow' & ettehkey-nci 'somehow' \\
way 'why' & way-nka 'for some reason' & way-nka 'for some reason' \\
\hline
\end{tabular}

Their instances are attested in the following examples:

(33) a. Nwukwu-nka-lul salangha-myen maum-i senhayci-nta. who-Q-ACC love-if heart-NOM become good-DCL 'If one loves someone, he/she feels better.' '(Lit.) If one loves whoever it is, he/she feels better.'

b. Nwukwu-nci nathana-myen tollyecwu-sey-yo. who-Q turn up-if return-HON-HEAR.HON 'If someone turns up, please return it to him/her.'

(34) a. Nay-ka mwe-nka-lul mek-canha-yo.

I-NOM what-Q-ACC eat-TAG-HEAR.HON

'I ate something, didn't I?'

b. Chithosu-i-nci mwe-nci sa-myen, kwaca an-ey Cheetos-COP-Q what-Q buy-if cookie inside-in iss-ten-ke-ntey. exist-PST-what-DCL 'If you buy Cheetos or what, it was in the cookie.' 
(35) a. Encey-nka hanpenccum-un tolapwacwu-keyss-cyo. when-Q one time-TOP turn around-will-HEAR.HON '(He) will turn around and see (me) at least one time sometime.'

b. Wuli-ka encey-nci pokey toy-myen tasi sanguyha-ca. We-NOM when-Q see -if again discuss-PROPO 'Let's discuss (it) again if we see each other.'

(36) a. Maypen eti-nka-ey kathinun kkwum-ul kkwu-nta-myen, ... every time where-Q-in locked up dream-ACC dream-DCL-if 'Every time I am locked somewhere, ...'

b. Tatul eti-nci-eyse cal sal-ki pala-nta. everyone where-Q-at well live-NM hope-DCL 'I hope that everyone lives well somewhere.'

(37)

$\begin{array}{lllll}\text { a. Na-nun } & \text { ettehkey-nka } & \mathrm{ku} & \text { kil-ul } & \text { alanay-1 keya. } \\ \text { I-TOP } & \text { how-Q } & \text { that } & \text { way-ACC } & \text { find-will }\end{array}$

'I will find the way somehow.'

b. Swukyengi-nun ettehkey-nci manhun ton-ul

Swukyeng-TOP how-Q a lot money-ACC

peleo-n kes kath-ass-ta.

earn-seem like-PST-DCL

'It seems that Swukyeng earned a lot of money.'

(38) a. Talli-nun mal wieyse-to ku-nun way-nka cakkwu galloping horse on-even he-TOP why-Q often sinkyeng-i kelly-ess-ta. nerve-NOM get on-PST-DCL 'Even riding on the horse, he got on his nerves for some reason.'

b. Anay-nun way-nci talkapci anh-un phyoceng-i-ta. wife-NOM why-Q happy not-MOD look-COP-DCL 'My wife looked not happy for reason.'

Suh (1987) and Chung (1996), among other Korean generative grammarians, provide a clausal analysis for indefinites in (32) derived from wh-elements plus Q-markers. In other words, the indefinites in question are created by indirect question clauses composed of a wh-element plus a copula '-i-' plus a Q-marker, 
which can also be understood as a wh-element on the cleft pivot corresponding to, for example, 'who(ever) it is?' in English (as in the literal English translation of (33a)). According to Kim (1992), this construction started in the $18^{\text {th }}$ century in the history of Korean. Though at first, it was of a clausal structure as a truncated indirect question, it has undergone a grammaticalization into a nominal structure. This means that the complementizers such as '-nka' and '-nci' in the process of grammaticalization were initially Q-markers, but they convert/grammaticalize to occupy the functional layer of a nominal structure for the newly created indefinites. In this regard, the indefinite use of wh-elements in Korean epitomizes another instance representing a dual function of an interrogative complementizer. At the same time, the availability of unselected EQs in Korean evidently makes a structural environment for the grammaticalization of a truncated indirect question clause into a nominal structure of an indefinite derived from a wh-element.

Regarding the role of the two Korean Q-markers with wh-elements in the nominal domains, we are in keeping with Erlewine (2019) on the relevant point. In his cross-linguistic study of indefinites derived from wh-phrases, Erlewine notes that in languages like Hungarian and Japanese, the particle that wh-phrases combine with to form indefinites serves semantically as a disjunctor. Erlewine goes on to propose that, in these languages, the surface realization of the disjunctor can correspond to the use of a junctor $(J)$ head or $\exists_{\text {reset }}$ alone. Clauses containing a wh-phrase or J-disjunction will have a denotation with no ordinary value, but with a non-trivial alternative set. However, $\exists_{\text {reset }}{ }^{6}$ ) applied to a wh-containing phrase results in an indefinite which satisfies semantic interpretability. Likewise, in Korean the grammaticalization from an indirect question clause to a indefinite nominal gives a right handle to '-nka' and '-nci' that combine with wh-elements and function as disjunctors.

\section{Conclusion}

Kim \& Tomioka (2014) investigate the theoretical, particularly semantic machinery necessary to account for the peculiar aspects of unselected EQs in Korean/

6) The operation of Reset is defined as follows:

(i) An operator Op is "resetting" if it lexically specifies [Op $\alpha]:=\left\{[\mathrm{Op} \alpha]^{\circ}\right\}$. 
Japanese. Building on Kim \& Tomioka's (ibid.) seminal study of them, in this paper we concentrate on the difference between Korean/Japanese and English/ Chinese in the distribution of unselected EQs. We ascribe the difference at issue to the availability of an overt Q-marker. In addition, when it is available, the overt Q-marker can take up another role as an adverbializer encoding reason/cause or motivation/purpose that represents the relation between EQ clauses and their host main clauses. In other words, in head-final languages such as Korean and Japanese, the overt Q-marker in the final position of embedded clauses they can be more readily grammaticalized into an adverbializer; other non-Q complementizers in these languages are also predicted to follow suit, which is evidently the case. Thus, the peculiar distribution of unselected EQs boils down to the dual function of an interrogative complementizer in Korean/Japanese.

Note, though, that the dual function of an overt complementizer is not confined to head-final languages. For example, in English as a head-initial language the non-Q complementizer 'that' or the complementizer-lacking infinitival marker 'to' can also serve multiple functions, as follows.

(39) a. The girl that was watched a movie with by me came to visit.

b. He was so poor that he couldn't buy the car.

(40) a. The next train to leave from Platform 5 is the 17.30 to Bristol.

b. She came here to see me.

The (a)-examples of (39) and (40) illustrate the adjectival function of 'that' or 'to'-infinitival clauses, and their (b)-examples, the adverbial function of the clauses. To conclude, the overt realization of a complementizer can feed its conversion to other grammatical functions.7)

7) In (i) repeated from (31), '-ther' of 'whether' or '-ever' of 'whoever' arguably functions to reanalyze its amalgam with a moved wh-element as an overt complementizer, in the way suggested by Chomsky (2013) for English free relative clauses.

(i) [Whether Tom leaves or not] / [whether Tom leaves or stays] / [whatever Tom does,] Jon won't stay past midnight. (Gawron, 2001; Rawlins, 2006) 


\title{
References
}

Chomsky, N. (2013). Problems of projection. Lingua, 130, 33-49.

Chung, D. (1996). On the representation and Licensing of $Q$ and $Q$-dependency. (Ph.D. Dissertation). University of Southern California.

Erlewine, M. Y. (2019). Wh-quantification in alternative semantics. A Paper Presented at GLOW in Asia XII, Dongguk University, Seoul.

Gawron, J. M. (2001). Universal concessive conditionals and alternative NPs in English. In C. Condoravdi \& G. R. de Lavalette (Eds.), Logical perspectives on language and information, 73-106. CSLI Publications.

Kim, C. (1992). Kwukeuy Uymwunsawa Pwucengsaey Kwanhan Yenkwu: A Study on Korean Interrogatives and Indefinites. (Ph.D. dissertation). Hanyang University, Seoul.

Kim, J., \& Tomioka, S. (2014). Two types of unselected embedded questions. In Proceedings of WCCFL 31.

Lascarides, A., \& Nicholas A. (1993). Temporal interpretation, discourse relations and commonsense entailment. Linguistics and Philosophy, 16.5, 437-493.

Liu, H. (2004). Complex predicates in Mandarin Chinese: Three types of 'Bu-Yu' structures. (Ph.D. Dissertation). University of California, Los Angeles.

Özyıldiz, D. (2018). Unselected questions. A paper read at The WAFL 14.

Potts, C. (2005). The logic of conventional implicatures. Oxford University Press, USA.

Rawlins, Kyle. (2006). (Un)conditionals: An investigation in the syntax and semantics of conditional structures. (Ph.D. Dissertation), University of California, Santa Cruz.

Rhee, S. -H. (2017). From false promises, fake quotations, and feigned questions into grammar: Grammaticalization of manipulative discourse strategies. An invited talk at The 25th Japanese/Korean Linguistics held at The University of Hawaii, Manoa.

Suh, C. M. (1987). Kwuke Uymuwnmwun Yenkwu: A study on Korean Questions. Thap Press.

\author{
Myung-Kwan Park \\ Professor \\ Department of English \\ Dongguk University \\ 30, Phildong-ro 1-gil, Jung-gu, Seoul 04620, Korea \\ E-mail:parkmk@dongguk.edu
}

Received: June 29, 2021

Revised version received: August 15, 2021

Accepted: August 23, 2021 